\title{
COMUNICAÇÃO
}

\section{OBTENÇÃO DE LINHAGENS DE Lentinula edodes RESISTENTES A TEMPERATURAS ELEVADAS E SELEÇÃO DE LINHAGENS RESISTENTES AO Trichoderma sp.}

\author{
Obtention of Lentinula edodes strains resistant to high \\ temperatures and selection of strains resistant to Trichoderma sp.
}

\author{
Nelson Menolli Junior ${ }^{1}$, Luzia Doretto Paccola-Meirelles ${ }^{2}$
}

\begin{abstract}
RESUMO
Lentinula edodes (Berk.) Pegler (shiitake) é o segundo cogumelo mais consumido no mundo e sua produção pode ser feita em toras de madeira ou em cultivo axênico utilizando resíduos agroindustriais como substrato. O cultivo do shiitake no Brasil tem sido gravemente prejudicado pela alta incidência de fungos contaminantes, como Trichoderma sp., e pela ausência de linhagens mais adaptadas às temperaturas tropicais. Duas linhagens resistentes ao Trichoderma sp. foram obtidas por meio de seleção quando crescidas em contato com o fungo contaminante e, por meio de fragmentação micelial, foram obtidas linhagens resistentes a temperaturas elevadas, capazes de crescer a $30^{\circ} \mathrm{C}$ em meio de cultura.
\end{abstract}

Termos para indexação: Shiitake, cogumelos comestíveis, resistência ao calor, dedicariotização.

\begin{abstract}
Lentinula edodes (Berk.) Pegler (shiitake) is the second most consumed mushroom in the world and its production can be made in natural logs or in axenic culture using agroindustrial residues as substrate. The cultivation of shiitake in Brazil has been seriously harmed by the high incidence of contaminant fungi such as Trichoderma sp. and by the absence of strains adapted to tropical temperatures. Two strains resistant to Trichoderma sp. were obtained by selection when grown in contact with the contaminant fungus and, by mycelial fragmentation, strains were obtained that can resist high temperatures and grow at $30^{\circ} \mathrm{C}$ in a culture medium.
\end{abstract}

Index terms: Shiitake, edible mushrooms, heat resistance, dedikaryotization.

(Recebido em 13 de junho de 2008 e aprovado em 9 de março de 2009)

Lentinula edodes (Berk.) Pegler, é um basidiomiceto cujo basidioma apresenta alto valor gastronômico destacando-se não só pelo seu agradável sabor como também por suas propriedades nutricionais e terapêuticas. Representa uma importante fonte de compostos bioativos, como proteínas lipídios, carboidratos, vitaminas, fibras e minerais essenciais (Chang \& Miles, 1989; Terashita et al., 1990), além de princípios ativos com função antitumoral (Chibata et al., 1969; Maeda et al., 1998), anticarcinogênica (Sugano et al., 1985), antiviral (Kobayashi et al., 1987; Suzuki et al., 1990; Sarkar et al., 1993) e hipocolesterolêmica (Chibata et al., 1969; Sugiyama et al., 1995).

A produção do shiitake pode ser feita em toras de madeira, sendo esse o método tradicional utilizado a mais de 900 anos, ou em cultivo intensivo no qual são utilizados blocos de serragem suplementados com nutrientes (Zhanxi \& Zhanhua, 2001). Para o cultivo intensivo, diversos resíduos agrícolas vêm ganhando espaço na produção comercial desse cogumelo, como bagaço de cana e palha ou sabugo de milho (Eira \& Minhoni, 1997; Rossi, 1999; Royse, 2001). Nesse sistema de cultivo intensivo, o ciclo de produção é mais rápido, mais controlado e demonstra uma eficiência biológica mais elevada quando comparados ao sistema tradicional (Przybylowicz \& Donoghue, 1990; Levanon et al., 1993). Além disso, a suplementação do substrato com farelos como os de trigo, arroz, soja ou milho disponibilizam mais nutrientes, proporcionando melhor desenvolvimento micelial (Royse, 1985, 2001; Iizuka, 1997; Silva et al., 2005).

A cultura, tanto no sistema de cultivo em toras como em substratos sintéticos, tem sido prejudicada pela competição com outros fungos, entre eles várias espécies do gênero Trichoderma que têm causado sérios problemas na produção (Badham, 1991). Entretanto, sob condições

\footnotetext{
${ }^{1}$ Instituto Federal de Educação, Ciência e Tecnologia de São Paulo/IFSP - Campus São Paulo - Rua Pedro Vicente - 625 - Canindé - $01109-010$ - São Paulo, SP - menollijr@yahoo.com.br

${ }^{2}$ Universidade Estadual de Londrina/UEL - Departamento de Biologia Geral - Londrina, PR
}

Ciênc. agrotec., Lavras, v. 34, Edição Especial, p. 1640-1646, 2010 
nutritivas adequadas e temperaturas favoráveis, algumas linhagens de $L$. edodes demonstraram resistência ao Trichoderma sp. (Ishikawa et al., 1980; Badham, 1991).

No Brasil, o cultivo do shiitake vem crescendo principalmente nas regiões sul e sudeste que possuem condições climáticas mais favoráveis (Ishikawa et al., 2001). Com a expansão da cultura cresce também a necessidade de linhagens mais eficientes e mais adaptadas às condições regionais, o que pode ser obtido por meio do melhoramento genético.

O melhoramento de linhagens de cogumelos comestíveis pode ser conduzido de diferentes maneiras e é dependente do ciclo de vida da espécie. Durante seu ciclo de vida o L. edodes apresenta dois tipos de micélio: o micélio primário e o micélio secundário. $\mathrm{O}$ micélio primário também conhecido como monocariótico, desenvolve-se a partir de um esporo sexual, o basidiósporo. O micélio secundário, também conhecido como micélio dicariótico é derivado do micélio primário e é constituído por hifas binucleadas e heterocarióticas. A formação do micélio secundário envolve uma interação entre dois micélios homocarióticos compatíveis. A primeira etapa para a formação desse micélio secundário é a fusão de duas hifas uninucleadas compatíveis (plasmogamia). Uma vez fusionada, a célula torna-se binucleada e heterocariótica. O segundo passo é o estabelecimento do dicarion, ou seja, a formação do micélio dicariótico a partir dessa única célula binucleada (Paccola-Meirelles, 2002).

Métodos convencionais, como isolamento, seleção de linhagens e cruzamento monospóricos e fusão de protoplastos, são as técnicas mais empregadas atualmente no melhoramento genético de shiitake (Chang et al., 1993).

Visando a condução de um programa de melhoramento genético em L. edodes, objetivou-se, neste trabalho, selecionar linhagens resistentes ao fungo contaminante Trichoderma sp. e obter linhagens resistentes a temperatura elevadas.

Foram utilizadas 47 linhagens de L. edodes, depositadas no banco de germoplasma fúngico do Laboratório de Genética de Microrganismos da Universidade Estadual de Londrina UEL/CCB/BIO, as quais foram mantidas em meio de cultura Batata Dextrose Ágar (BDA). A temperatura ótima de crescimento dessas linhagens foi de $25^{\circ} \mathrm{C}$.

As 47 linhagens de shiitake foram avaliadas quanto à resistência ao Trichoderma sp. Para isso, em um primeiro ciclo de seleção, discos miceliais, de $10 \mathrm{~mm}$ de diâmetro, retirados das extremidades das colônias de shiitake, foram inoculados na periferia de uma placa de placa de Petri contendo meio BDA. Após seis dias de incubação a $25^{\circ} \mathrm{C}$, um disco micelial (10 mm diâm.) de Trichoderma sp. foi inoculado no centro da placa, e essas reincubadas a $25^{\circ} \mathrm{C}$. Foram combinadas em uma mesma placa, quatro linhagens de shiitake nas extremidades para cada disco micelial de Trichoderma sp. ao centro. As linhagens de shiitake que apresentaram crescimento, mesmo esse sendo mínimo, após sete dias de contato com o antagonista Trichoderma sp., foram selecionadas e testadas individualmente na presença do fungo antagonista. Para esse segundo "screening", as linhagens selecionadas foram inoculadas em uma extremidade da placa de Petri contendo meio BDA e após oito dias de crescimento a $25^{\circ} \mathrm{C}$, na extremidade oposta da mesma placa, foram inoculados os discos miceliais de Trichoderma sp. A avaliação das linhagens consideradas resistentes foi feita em duplicata, dez dias após a inoculação do Trichoderma sp., através da visualização da formação de uma zona de inibição na região limítrofe de contato entre os dois inóculos.

Para o melhoramento e seleção de linhagens resistentes à temperatura, foram selecionadas aleatoriamente 25 linhagens de L. edodes da coleção de fungos do Laboratório de Genética de Microrganismos $\mathrm{UEL} / \mathrm{CCB} / \mathrm{BIO}$. Essas foram inoculadas em meio BDA e incubadas a $30^{\circ} \mathrm{C}$, durante 18 dias. Após esse período foram selecionadas nove linhagens que apresentaram melhor desenvolvimento a essa temperatura, sendo então cultivadas em meio BDA até a colônia atingir quatro centímetros de diâmetro. O micélio das extremidades dessas colônias foi seccionado com auxílio de um bisturi obtendose inúmeros microfragmentos. Os microfragmentos, oriundos das nove diferentes linhagens, foram misturados em meio caldo de batata e homogeneizados em vortex, durante aproximadamente $30 \mathrm{~s}$. Uma alíquota de $0,1 \mathrm{~mL}$ de cada suspensão foi adicionada em pocinhos de $10 \mathrm{~mm}$ de diâmetro em placas de Petri contendo meio BDA. Em cada placa de Petri foram feitos quatro pocinhos. O material foi incubado a $30^{\circ} \mathrm{C}$ durante sete dias. Após esse período, setores emergentes do inóculo foram isolados e selecionados para avaliação do crescimento radial $(\mathrm{mm})$ a $30^{\circ} \mathrm{C}$ e posterior comparação com o crescimento de seus parentais, na mesma temperatura. Os resultados foram submetidos à análise de variância e comparação das médias, pelo teste de Scott-Knott a 5\% de significância.

Em um primeiro ciclo de seleção para resistência ao Trichoderma sp. (Figura 1), foram selecionadas somente cinco linhagens de shiitake (48R, 46R, Lin.75, Lin.56 e Cris79). Após o segundo ciclo de seleção, três linhagens foram consideradas suscetíveis ou moderadamente resistentes (48R, Lin.75, Lin.56) e duas (46R e Cris79) resistentes (Figura 2). As duas linhagens resistentes 46R e Cris79 
cresceram vigorosamente na presença do antagonista, não apresentando nenhuma alteração na morfologia do micélio e formaram uma zona de inibição bem definida na região de contato entre os dois fungos (Figura 2).

Outras medidas de prevenção aos fungos contaminantes no cultivo de shiitake têm sido recomendadas, como borrifar álcool comercial (70\%) ou uma solução de hipoclorito de sódio (Pascholati et al., 1998), bem como o uso de hidróxido de cálcio (Eira \& Minhoni, 1997; Andrade \& Graciolli, 2005) ou fungicidas (Mata \& Gaitàn-Hernández, 1994; Andrade \& Graciolli, 2005). Porém, algumas dessas alternativas como a utilização de hidróxido de cálcio e aplicação do fungicida Benomyl podem ocasionar queda de produtividade e perda da qualidade dos basidiomas, conforme observado por Andrade \& Graciolli (2005). Assim, a busca de linhagens resistentes ao Trichoderma sp. é uma alternativa recomendada, já que sob condições nutritivas e de temperatura favoráveis, algumas linhagens de L. edodes demonstram ser mais resistentes ao ataque pelo Trichoderma sp. (Badham, 1991) devido, entre outros fatores, à ação de enzimas lignolíticas do shiitake, produzidas para degradar polímeros de lignina, que têm um importante papel na defesa contra o ataque do Trichoderma sp. (Hatvani et al., 2002).

Através da mistura de microfragmentos miceliais das nove linhagens de L. edodes que cresceram a $30^{\circ} \mathrm{C}$, foram obtidos 56 setores. Após seleção e isolamento, cada setor passou a ser denominado de linhagem "JR", seguida da numeração correspondente. Dessas linhagens, 28 foram submetidas à determinação do crescimento radial a $30^{\circ} \mathrm{C}$.
O crescimento foi acompanhado até o $16^{\circ}$ dia, quando pelo menos uma linhagem colonizou a placa por completo. A taxa de crescimento foi então comparada às das linhagens parentais envolvidas na mistura.

As linhagens parentais Lin.52, Lin.61, Lin.76 e Lin.79 indicaram o melhor crescimento radial na temperatura de $30^{\circ} \mathrm{C}$, sendo assim consideradas tolerantes. Já a Lin.56 foi a linhagem parental que apresentou menor taxa de crescimento micelial nas condições experimentais. Todos os setores selecionados, com exceção de JR50, apresentaram crescimento significativamente superior ao da linhagem parental Lin.56; porém nenhum deles com crescimento superior aos das linhagens parentais tolerantes (Figura 3).

Cerca de $21,4 \%$ dos setores apresentaram crescimento distinto de qualquer uma das linhagens parentais. Nesta classe estão incluídas as linhagens JR04, JR17, JR19, JR28, JR42 e JR49, as quais foram consideradas recombinantes. Uma hipótese que explicaria o surgimento destes recombinantes tem por base a ocorrência de um processo conhecido por dedicariotização, que é a recuperação dos dois componentes monocarióticos, a partir de linhagens dicarióticas. Nesse processo, a intensa microfragmentação micelial seguida da homogeneização pode ter ocasionado a separação mecânica dos dois núcleos presentes na região terminal da hifa dicariótica, originando os chamados neohaplontes, fragmentos portadores de um dos núcleos do micélio dicariótico (Walser et al., 2001). Assim, dicarions e monocarions (neohaplontes) estariam presentes nas misturas contendo os microfragmentos. Após a inoculação da mistura nos pocinhos em meio de cultura, um neohaplonte pode ter

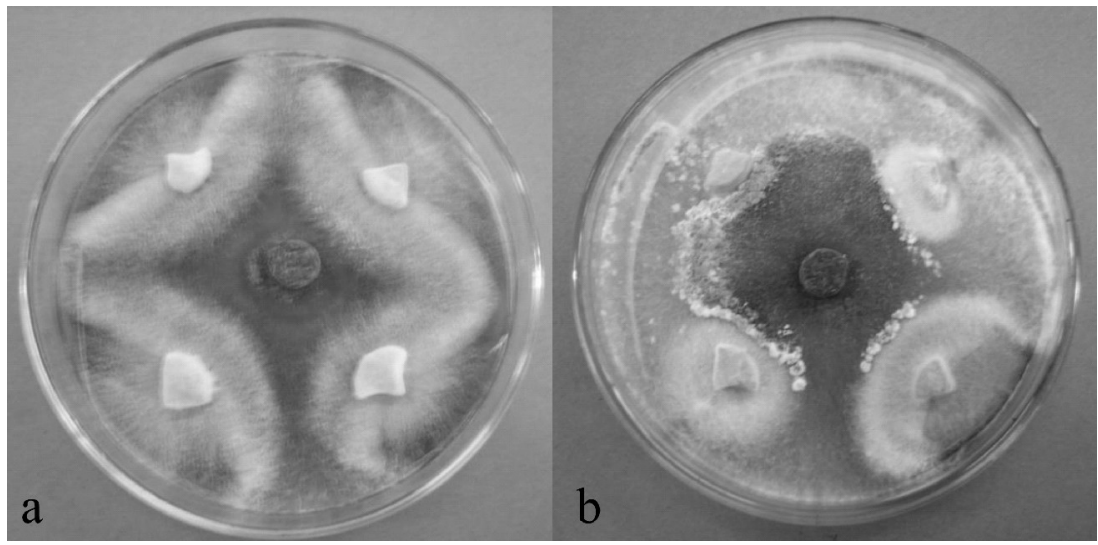

Figura 1 - Primeiro ciclo de seleção entre as linhagens de shiitake, inoculadas na extremidade da placa, para resistência ao Trichoderma sp., inoculado ao centro. a) Linhagens que apresentaram algum grau de resistência. b) Linhagens consideradas suscetíveis. (Avaliação após sete dias da inoculação do Trichoderma sp. em meio de cultura BDA, placas incubadas a $\left.25^{\circ} \mathrm{C}\right)$.

Ciênc. agrotec., Lavras, v. 34, Edição Especial, p. 1640-1646, 2010 
sido dicariotizado pela migração de um núcleo compatível do microfragmento dicariótico para um neohaplonte, originando assim os recombinantes. Esse processo de transferência de um núcleo de um dicarion para um monocarion foi descrito por Buller (1931) e posteriormente denominado de cruzamento di-mon por Papazian (1950). Segundo Raper (1966) esse é um fenômeno comum na natureza e tem sido reportado em diferentes espécies de fungos (Dickson, 1934; Nogami et al., 2002).

Dentre os recombinantes, a linhagem JR36 apresentou o melhor resultado de crescimento radial a $30^{\circ} \mathrm{C}$ (Figura 3), enquanto que o recombinante JR50 apresentou menor crescimento micelial nos 16 dias de incubação.

O shiitake é um fungo de clima temperado e sua temperatura ótima de crescimento encontra-se entre $24 \mathrm{e}$ $27^{\circ} \mathrm{C}$. No entanto, as linhagens podem ser adaptadas a uma ampla variação de temperatura e podem tolerar temperaturas baixas para crescimento, mas têm se apresentado muito vulneráveis a temperaturas altas, já que o micélio do shiitake paralisa seu crescimento em temperaturas acima de $34^{\circ} \mathrm{C} \mathrm{e}$ morre em temperaturas acima de $40^{\circ} \mathrm{C}$ (Chen, 2005).

A maior dificuldade em trabalhos de melhoramento é encontrar linhagens híbridas com as características agronômicas desejáveis, pois a expressão poderá ser modificada pelas condições de crescimento (Elliott \& Langton, 1981). As técnicas convencionais de melhoramento, como o cruzamento monospórico e o pareamento micelial seguido de seleção, em geral são trabalhosas e demoradas. Assim essa técnica de fragmentação micelial seguida da mistura entre linhagens portadoras de características desejáveis pode representar uma alternativa interessante para auxiliar na condução de um programa de melhoramento em L. edodes.

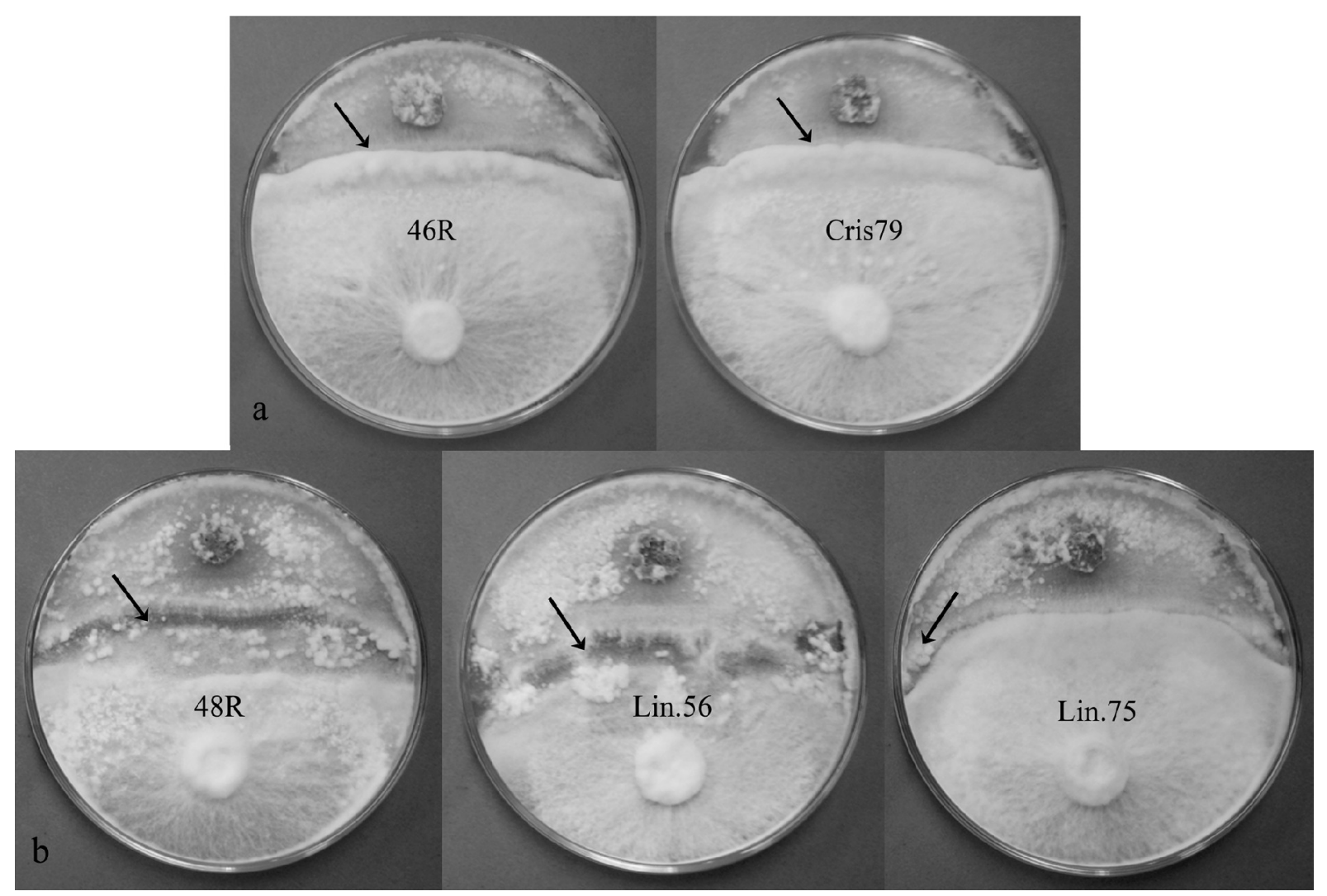

Figura 2 - Reação das linhagens de shiitake em contato com o antagonista Trichoderma sp. Os dois fungos foram inoculados nas extremidades opostas da placa. Avaliação após dez dias da inoculação do Trichoderma sp. em meio de cultura BDA, placas incubadas a $25^{\circ} \mathrm{C}$. a) Linhagens de shiitake (46R e Cris 79) consideradas resistentes ao Trichoderma sp. As setas indicam as zonas de inibição na região de contato entre os dois fungos. b) Linhagens consideradas suscetíveis (48R, Lin.56) ou moderadamente resistentes (Lin.75). As setas indicam o avanço micelial da colônia de Trichoderma sp. sobre o shiitake. 


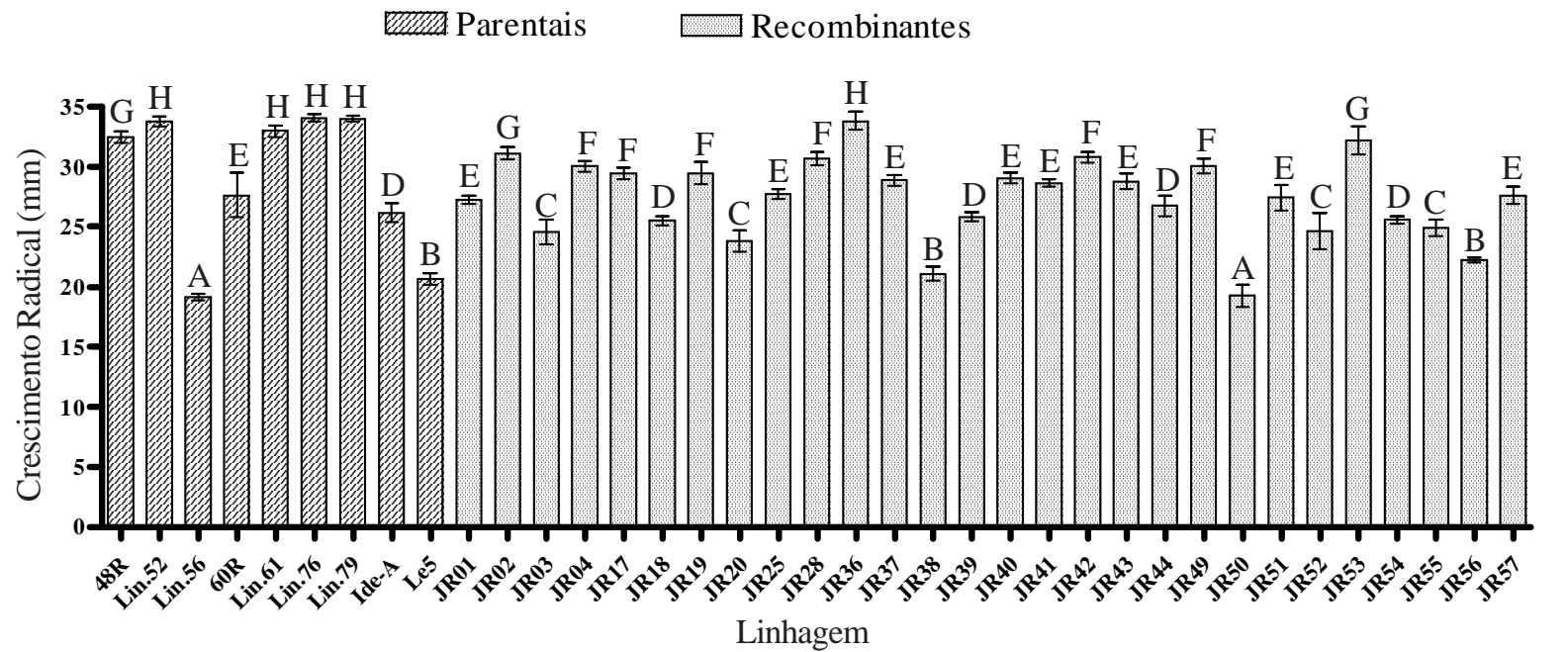

Figura 3 - Crescimento radial (mm) das linhagens parentais e recombinantes de L. edodes no $16^{\circ}$ dia de incubação a $30^{\circ} \mathrm{C}$ em meio de cultura. As médias seguidas pela mesma letra não diferem entre si pelo teste de agrupamento de ScottKnott, a 5\% de probabilidade.

Embora nenhuma linhagem com característica de resistência à temperatura superior aos parentais tolerantes tenha sido obtida, foi possível a recuperação de recombinantes distintos dos parentais que apresentaram bom desenvolvimento micelial a $30^{\circ} \mathrm{C}$, sendo consideradas linhagens promissoras para experimentos de cultivo. Já os testes de resistência ao Trichoderma sp. permitiram selecionar duas linhagens consideradas resistentes, Cris79 e 46R.

Para que as linhagens do banco de linhagens e as obtidas por recombinação caracterizadas neste trabalho sejam utilizadas no cultivo, são necessários experimentos em escala de produção para observar o comportamento das linhagens e a qualidade dos cogumelos obtidos.

\section{AGRADECIMENTOS}

À Dra. Viviani Vieira Marques Marçal, pelo auxílio nas análises estatísticas e ao Conselho Nacional de Desenvolvimento Científico e Tecnológico (CNPq), pelo auxílio financeiro, através da concessão de bolsa ao primeiro autor.

\section{REFERÊNCIASBIBLIGRÁFICAS}

ANDRADE, M.C.N.; GRACIOLLI, L.A. Controle de fungos contaminantes no cultivo do cogumelo comestível shiitake em toros de eucalipto. Acta Scientiarum Agronomy, Maringá, v.27, n.2, p.239-299, 2005.
BADHAM, E.R. Growth and competition between Lentinus edodes and Trichoderma harzianum on sawdust substrates. Mycologia, Lawrence, v.83, n.4, p.455-463, 1991.

CHANG, S.T.; BUSWELL, J.A.; MILES, P.G. Genetics and breeding of edible mushrooms. Amsterdam: Gordon and Breach Science, 1993. 329p.

CHANG S.T.; MILES, P.G. Edible mushrooms and their cultivation. Boca Raton: CRC, 1989. 345p.

CHEN, A.W. What is shiitake? In: GUSH, R. (Ed.). Mushroom grower's handbook 2. Seoul: MushWorld, 2005. p.3-16.

CHIBATA, I.; OKUMURA, K.; TAKEYAMA, S.;

KOTERA, K. Lentinacin: a new hypocholesterolemic substance in Lentinus edodes. Cellular and Molecular Life Sciences, Basel, v.25, n.12, p.237-1238, 1969.

DICKSON, H. Studies in Coprinus sphaerosporus: I., the pairing behavior and the characteristics of various haploid and diploid strains. Annals of Botany, London, v.48, n.3, p.527-547, 1934.

EIRA, A.F.; MINHONI, M.T.A. Manual teórico-prático do cultivo de cogumelos comestíveis. 2.ed. Botucatu: Fundação de Estudos e Pesquisas Agrícolas e Florestais, 1997. 115p. 
ELLIOTT, T.J.; LANGTON, F.A. Strain improvement in the cultivated mushroom Agaricus bisporus. Euphytica, Netherlands, v.30, n.1, p.175-182, 1981.

HATVANI, N.; KREDICS, L.; ANTAL, Z.; MÉCS, I. Changes in activity of extracellular enzymes in dual cultures of Lentinula edodes and mycoparasitic Trichoderma strains. Journal of Applied Microbiology, Oxford, v.92, n.3, p.415-423, 2002.

ISHIKAWA, H.; NAGAO, M.; OKI, T.; KAWABE, K. Physiological changes in Lentinus edodes (Berk.) Sing. mycelia induced by Trichoderma metabolities. Reports of the Tottori Mycological Institute, Tottori, n.18, p.197-204, 1980.

ISHIKAWA, N.K.; KASUYA, M.C.M.; VANETTI, M.C.D. Antibacterial activity of Lentinula edodes grown in liquid medium. Brazilian Journal of Microbiology, São Paulo, v.32, n.3, p.206-210, 2001.

KOBAYASHI, N.; HIRAMATSU, A.; AKATSUKA, T. Purification and chemical properties of an inhibitor of plant virus infection from fruiting bodies of Lentinus edodes. Agricultural and Biological Chemistry, Tokyo, v.51, n.3, p.883-890, 1987.

LEVANON, D.; ROTHSCHILD, N.; DANAI, O.; MASAPHY, S. Bulk treatment of substrate for the cultivation of shiitake mushrooms (Lentinula edodes) on straw. Bioresource Technology, Amsterdam, v.45, n.1, p.63-64, 1993.

MAEDA, Y.Y.; TAKAHAMA, S.; YONEKAWA, H. Four dominant loci for the vascular responses by the antitumor polysaccharide, lentinan. Immunogenetics, Heidelberg, v.47, n.2, p.159-165, 1998.

MATA, G.; GAITÀN-HERNÁNDEZ, R. Avances en el cultivo de shiitake en pulpa de café. Revista Iberoamericana de Micologia, Bilbao, v.11, n.1, p.90-91, 1994.

NOGAMI, T.; KAMEMOTO, Y.; OHGA, S.; KITAMOTO, Y. The buller phenomenon in a bipolar basidiomycetous mushroom, Pholiota nameko.

Micología Aplicada Internacional, Puebla, v.14, n.2, p.1118, 2002.

PACCOLA-MEIRELLES, L.D. Genética e melhoramento de cogumelos comestíveis. In: MELO, I.S.; VALADARES-INGLIS, M.C.; NASS, L.L.; VELOIS,
A.C.C. (Orgs.). Recursos genéticos \& melhoramento: microrganismos. Jaguariúna: Embrapa Meio Ambiente, 2002. v.1, p.357-392.

PAPAZIAN, H.P. Physiology of the incompatibility factors in Schizophyllum commune. Botanical Gazette, Chicago, v.112, n.2, p.143-163, 1950.

PASCHOLATI, S.F.; STANGARLIN, J.R.; PICCININ, E. Cogumelos: cultivo e comercialização (shiitake e cogumelo do sol). Cuiabá: Sebrae/MT, 1998. 85p. (Coleção agroindústria, 17).

PRZYBYLOWICZ, P.; DONOGHUE, J. Shiitake grower's handbook: the art and science of mushroom cultivation. Dubuque: Kendall, 1990. 217p.

RAPER, J.R. Genetics of sexuality in higher fungi. New York: Ronald, 1966. 283p.

ROSSI, I.H. Suplementação de bagaço de cana para cultivo axênico do cogumelo Shiitake [Lentinula edodes (Berk.) Pegler]. 1999. 120p. Dissertação (Mestrado em Microbiologia)-Universidade Estadual Paulista "Júlio de Mesquita Filho”, Jaboticabal, 1999.

ROYSE, D.J. Cultivation of Shiitake on synthetic and natural logs. Pennsylvania: College of Agricultural Sciences, 2001. 10p.

ROYSE, D.J. Effect of spawn run time and substrate nutrition on yield and size of the shiitake mushroom. Mycologia, Lawrence, v.77, n.5, p.756-762, 1985.

SARKAR, S.; KOGA, J.; WHITLEY, R.J.; CHATTERJEE, S. Antiviral effect of the extract of culture medium of Lentinus edodes mycelia on the replication of herpes simplex virus type 1. Antiviral Research, Amsterdam, v.20, n.4, p.293-303, 1993.

SILVA, E.M.; MACHUCA, A.; MILAGRES, A.M.F. Effect of cereal brans on Lentinula edodes growth and enzyme activities during cultivation on forestry waste. Letters in Applied Microbiology, Oxford, v.40, n.4, p.283-288, 2005.

SUGANO, N.; CHOJI, Y.; HIBINO, Y.; YASUMURA, S.; MAEDA, H. Anticarcinogenic action of an alcoholinsoluble fraction (LAP1) from culture medium of Lentinus edodes mycelia. Cancer Letters, Amsterdam, v.27, n.1, p.1-6, 1985. 
SUGIYAMA, K.; AKACHI, T.; YAMAKAWA, A.

Eritadenia-induced alteration of hepatic phospholipid metabolism in relation to its hypocholesterolemic action in rats. Journal of Nutritional Biochemistry, Amsterdam, v.6, n.2, p.80-87, 1995.

TERASHITA, T.; KONO, M.; MISHIMA, N.; OBATA, T.; YAMAUCHI, M. The proximate components, free and protein bound amino acids in protein and 5'-GMP in fruit bodies of Lentinus edodes Singer (Shiitake mushroom) growth on artificial bed-blocks. Journal of the Japanese Society for Food Science and Technology, Ibaraki, v.37, n.7, p.528-532, 1990.

WALSER, P.J.; HOLLENSTEIN, M.; KLAUS, M.J.; KUES, U. Genetic analysis of basidiomycete fungi. In: TALBOT, N. (Ed.). Molecular and cellular biology of filamentous fungi: a practical approach. Oxford: Oxford University, 2001. p.59-88.

ZHANXI, L.; ZHANHUA, L. Juncao technology. Beijing: China Agricultural Scientech, 2001. 252p.

Ciênc. agrotec., Lavras, v. 34, Edição Especial, p. 1640-1646, 2010 